\title{
Nodular basal cell carcinoma of the face successfully treated with ingenol mebutate $0.015 \%$ gel
}

\author{
Silvia S. Iannazzone ${ }^{1}$, Vito Ingordo ${ }^{2}$
}

1 Outpatient Department of Dermatology, Benevento North-East District, Local Health Unit Benevento, Benevento, Italy 2 Outpatient Department of Dermatology, District n. 6, Local Health Unit Taranto, Taranto, Italy

Key words: ingenol mebutate, nodular basal cell carcinoma, non-melanoma skin cancer, therapy

Citation: Iannazzone SS, Ingordo V. Nodular basal cell carcinoma of the face successfully treated with ingenol mebutate $0.015 \%$ gel. Dermatol Pract Concept. 2018;8(2):129-131. DOI: https://doi.org/10.5826/dpc.0802a12

Received: October 5, 2017; Accepted: November 16, 2017; Published: April 30, 2018

Copyright: $\odot 2018$ Iannazzone et al. This is an open-access article distributed under the terms of the Creative Commons Attribution License, which permits unrestricted use, distribution, and reproduction in any medium, provided the original author and source are credited.

Funding: None.

Competing interests: The authors have no conflicts of interest to disclose.

All authors have contributed significantly to this publication.

Corresponding author: Vito Ingordo, MD, Via Pupino, 7, 74123 Taranto, Italy. Email: vito.ingordo@gmail.com

ABSTRACT Surgical excision is the first-choice treatment for basal cell carcinoma (BCC). Other treatments with topical agents such as 5-fluorouracil or imiquimod have also been suggested for use in superficial BCC (sBCC). Ingenol mebutate (IM) is a novel agent employed in the treatment of superficial actinic keratoses. The drug has been also successfully used in the treatment of sBCC. A case of large nodular BCC (nBCC) of the face in a 100-year-old inoperable woman is described. IM $0.015 \%$ gel was applied once daily for three consecutive days. This dose regimen was repeated for seven rounds within 11 months, with complete cure of the tumor. Mild local skin reactions, which were tolerated well, were observed. Selected cases of nBCC could be treated with IM gel, but the optimal concentration of the drug and the standard dose regimen of treatment are yet to be determined.

\section{Introduction}

Basal cell carcinoma (BCC) is the most frequent non-melanoma skin cancer. It has low mortality but a high morbidity. Surgical excision is the first-choice treatment for BCC, and Mohs micrographic surgery is the best treatment for the high-risk forms. Other physical treatments recommended are curettage and cautery, cryosurgery, carbon dioxide laser, photodynamic therapy (PDT) and radiotherapy. Topical treatment with 5-fluorouracil or imiquimod is also suggested for superficial BCC (sBCC) [1].

\section{Case Presentation}

A 100-year-old woman was visited in her home. She suffered from senile dementia with low mobility and lived permanently in bed. She had a large flesh-colored nodule on the left cheek that was eroded and covered by crusts (Figure 1). An incisional biopsy was performed, and histology confirmed the diagnosis of nodular BCC (nBCC). As the patient's situation did not lend itself toward surgical excision of the tumor or other physical therapies (curettage and cautery, cryosurgery, PDT, radiotherapy), treatment with topical ingenol mebutate 


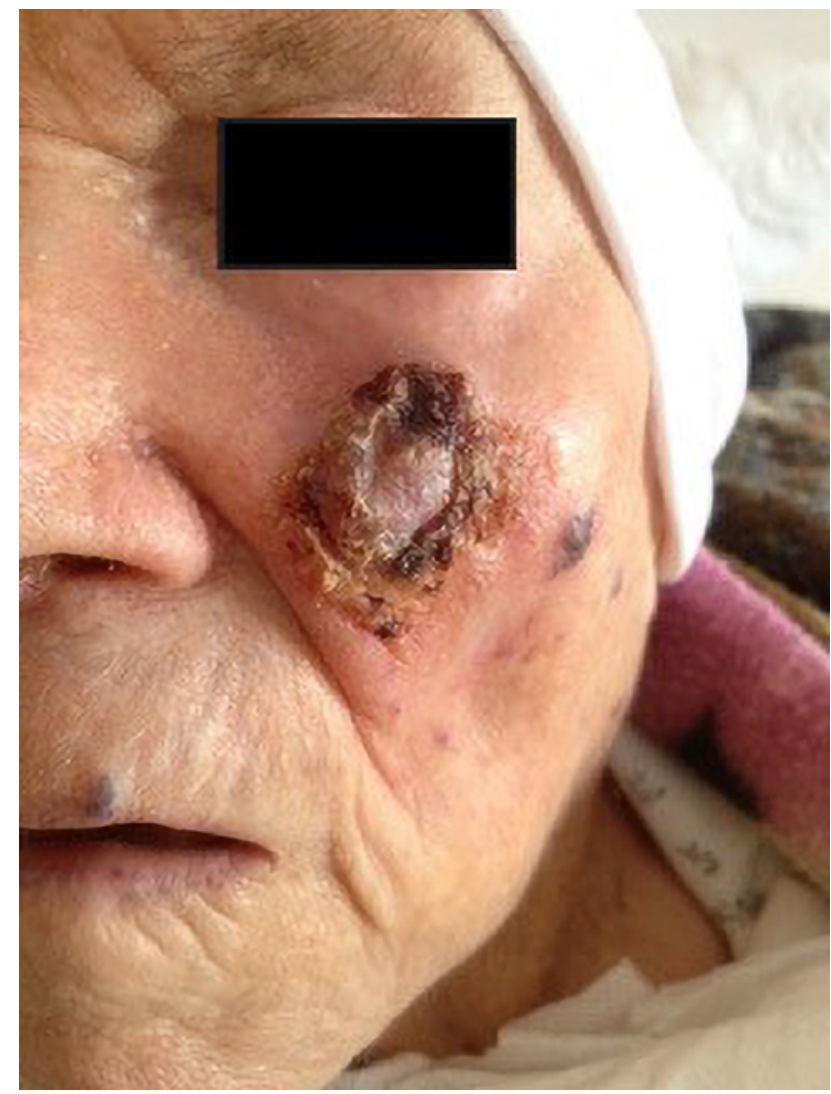

Figure 1. Clinical picture before treatment. [Copyright: @2018 Iannazzone et al.]

(IM) $0.015 \%$ gel was chosen. The gel was applied in the morning and washed after eight hours for three consecutive days. This dosing regimen was repeated once monthly for three consecutive months, and the tumor size progressively reduced (Figure 2). After six months the same dosing regimen was repeated four times (once monthly) until complete disappearance of the lesion was achieved (Figure 3). Six months later no relapse was observed. A local inflammatory response was observed after every application, consisting of erythema, scaling, and crusting. These skin reactions were tolerated well.

\section{Discussion}

IM is a novel agent extracted from the sap of the plant Euphorbia peplus, which has a dual mechanism of action consisting of rapid induction of primary necrosis followed by neutrophil-mediated, antibody-dependent cellular cytotoxicity of residual disease cells; the latter is partly mediated by protein kinase $\mathrm{C}$ activation [2]. This drug is registered in Italy for topical treatment of superficial actinic keratoses.

IM gel was first employed in the therapy of sBCC in a randomized phase IIA trial, using concentrations of drug of $0.0025 \%, 0.01 \%$, and $0.05 \%$. Two arms of treatment were started. The drug was applied on days 1 and 2 in the first arm and on days 1 and 8 in the second arm. The histologic

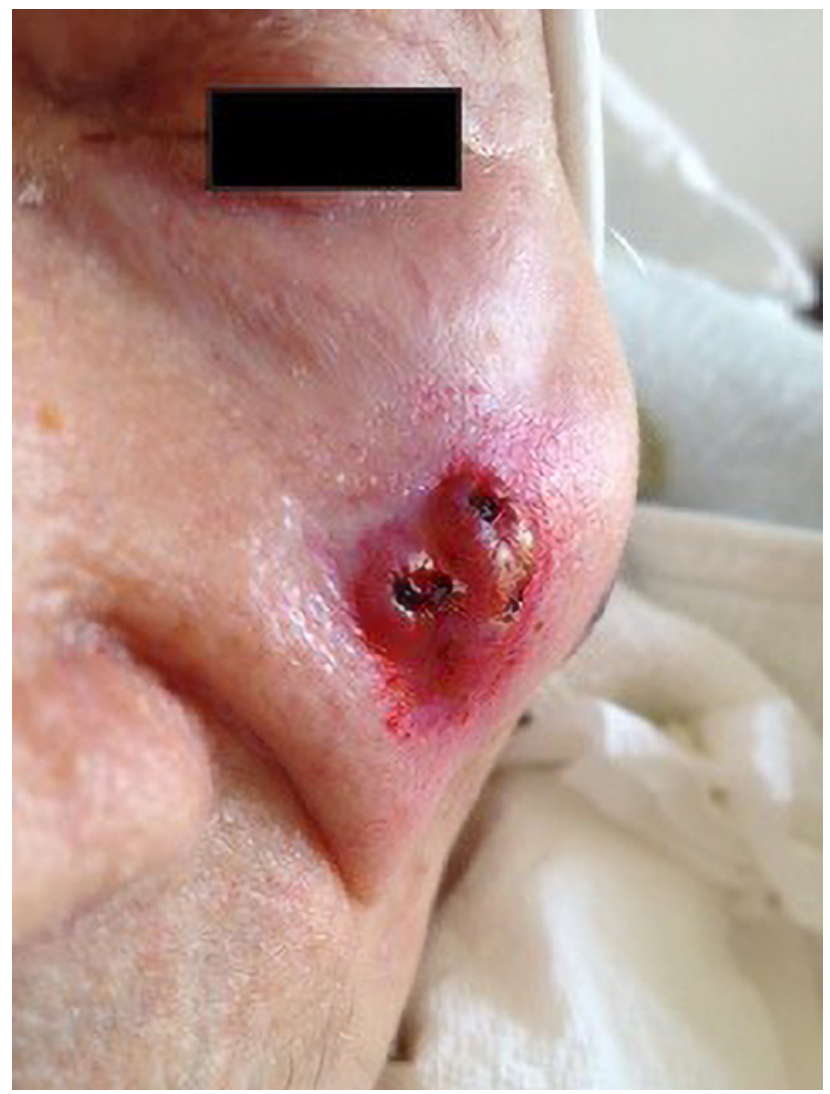

Figure 2. Clinical picture after 3 months of treatment. [Copyright: (C2018 Iannazzone et al.]

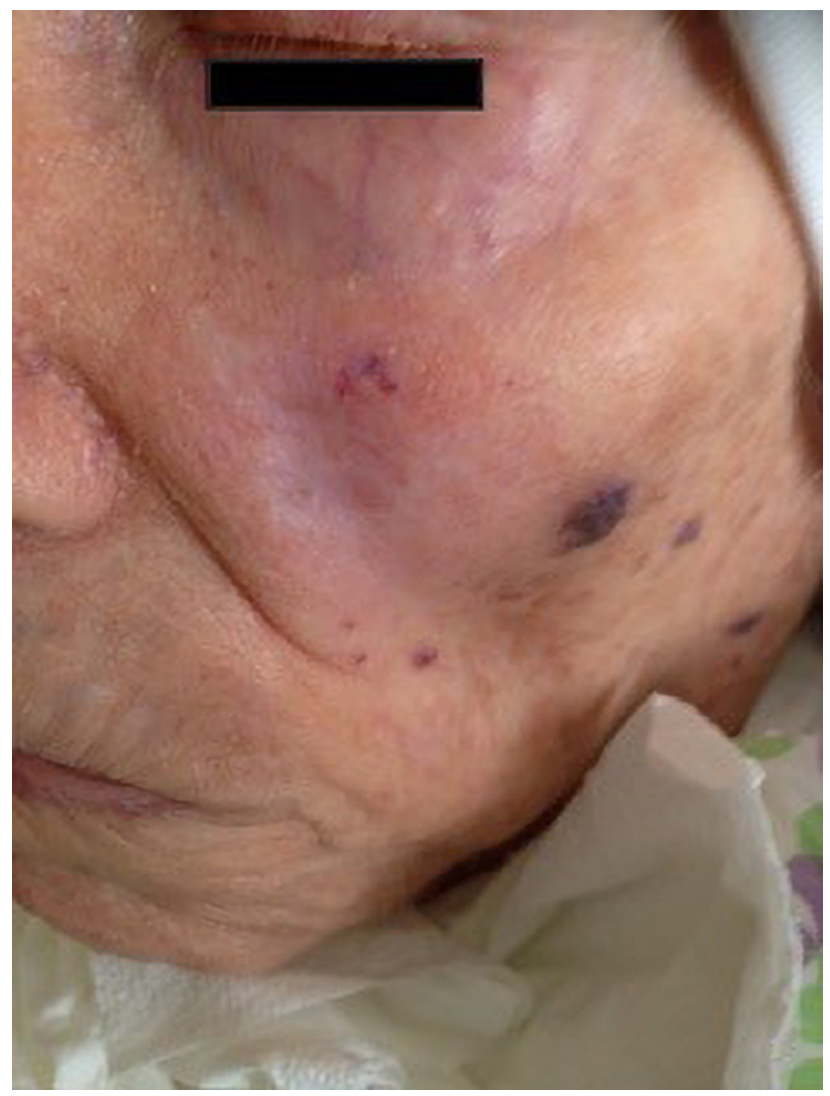

Figure 3. Clinical picture after 13 months of treatment. [Copyright: (C2018 Iannazzone et al.] 
clearance was $0 \%, 14 \%$ and $71 \%$ with the first dose regimen and $13 \%, 11 \%$ and $33 \%$ with the second dose regimen [2].

IM $0.05 \%$ gel was therefore used in the treatment of sBCC in single case reports, applied for two consecutive days and obtaining complete remission of lesions [3,4]. It was also used successfully at concentrations of $0.015 \%$ in a single case of sBCC, with two courses of four daily applications [5]. The concentration of $0.05 \%$ with the dose regimen of two daily applications was employed in treatment of sBCC in a 20-case series, achieving complete disappearance of the lesions in $100 \%$ of tumors. No recurrence was observed after six months [6]. Bettencourt also treated nine sBCCs using IM $0.05 \%$ gel, with occlusion by adhesive bandage in six lesions and no occlusion in three lesions. A lesion was treated for two days, two lesions were treated for four days, and all other lesions were treated for seven days. All sBCCs were clinically cured on short-term follow-up at 2-4 weeks. Biopsy of six of the nine lesions confirmed histologic clearance in all biopsy samples. No clinically suspicious lesion in any patients on subsequent follow-up evaluations at 3-month intervals was observed [7]. IM 0.05\% gel was also used in three pigmented BCC and the lesions were examined by dermoscopy and confocal microscopy before, during, and after the treatment [8]. Diluvio et al treated seven sBCC: two were treated with IM $0.015 \%$ gel for three consecutive days and five with IM $0.05 \%$ gel for two consecutive days. All the lesions were examined by dermoscopy before and after therapy, and dermoscopic patterns of BCC had disappeared. The clearance of tumors was also confirmed by histology [9]. Finally, a $2.5 \mathrm{~cm} \mathrm{nBCC}$ in a patient with multiple major medical problems was treated with IM gel $0.015 \%$ once daily applied on three consecutive days, resulting in the complete disappearance of the lesion [10].

\section{Conclusion}

According to the existing literature, this is the second case of nBCC successfully treated with IM gel. As the lesion was located on the face, we used a $0.015 \%$ concentration regimen. The therapy was well tolerated, but the length of treatment was long and several applications were needed due the low concentration of the drug.
In conclusion, selected cases of nBCC could be treated with IM gel, but the optimal concentration of the drug and the standard dose regimen of treatment are yet to be determined. More studies on larger series of cases are needed to confirm our hypotheses.

\section{Acknowledgements}

We wish to thank Andrea G. Tortora, MD, for revision of the manuscript.

\section{References}

1. Trakatelli M, Morton C, Nagore E, et al. BCC subcommittee of the Guidelines Committee of the European Dermatology Forum. Update of the European guidelines for basal cell carcinoma management. Developed by the Guideline Subcommittee of the European Dermatology Forum. Eur J Dermatol. 2014;24(3):31229.

2. Siller G, Rosen R, Freeman M, Welburn P, Katsamas J, Ogbourne SM. PEP005 (ingenol mebutate) gel for the topical treatment of superficial basal cell carcinoma: results of a randomized phase IIa trial. Australas J Dermatol. 2010;51(2):99-105.

3. Cantisani C, Paolino G, Cantoresi F, Faina V, Richetta AG, Calvieri S. Superficial basal cell carcinoma successfully treated with ingenol mebutate gel 0.05\%. Dermatol Ther. 2014;27:352-354.

4. Stieger M, Hunger RE. Ingenol mebutate treatment in a patient with Gorlin syndrome. Dermatology. 2016;232 (suppl 1):29-31.

5. Jung YS, Lee JH, Bae JM, Kim GM. Superficial basal cell carcinoma treated with two cycles of ingenol mebutate gel $0.015 \%$. Ann Dermatol. 2016;28(6):796-797.

6. Izzi S, Sorgi P, Piemonte P, Carbone, Frascione P. Successfully treated superficial basal cell carcinomas with ingenol mebutate $0.05 \%$ gel: report of twenty cases. Dermatol Ther (Heidelb). 2016;29:470-472.

7. Bettencourt MS. Treatment of superficial basal cell carcinoma with ingenol mebutate gel, $0.05 \%$. Clin Cosmet Investig Dermatol. 2016;9:205-209.

8. Monfrecola G, Scalvenzi M, Costa C, Cantelli MT, Fabbrocini G. Ingenol mebutate for pigmented superficial basal cell carcinomas: evaluation by confocal microscopy. G Ital Dermatol Venereol. 2016; Jun 10.

9. Diluvio L, Bavetta M, Di Prete M, Orlandi A, Bianchi L, Campione E. Dermoscopic monitoring of efficacy of ingenol mebutate in the treatment of pigmented and non-pigmented basal cell carcinomas. Dermatol Ther (Heidelb). 2017;30:e12438.

10. Del Rosso JQ. Ingenol mebutate topical gel. A status report on clinical use beyond actinic keratosis. J Clin Aesthet Dermatol. 2016;9 (11 Suppl 1):S3-S11. 